\title{
Assessment of respiratory system compliance with electrical impedance tomography using a positive end-expiratory pressure wave maneuver during pressure support ventilation: a pilot clinical study
}

Tobias H Becher*, Simon Bui, Günther Zick, Daniel Bläser, Dirk Schädler, Norbert Weiler and Inéz Frerichs

\begin{abstract}
Introduction: Assessment of respiratory system compliance $\left(\mathrm{C}_{\mathrm{rs}}\right)$ can be used for individual optimization of positive end-expiratory pressure (PEEP). However, in patients with spontaneous breathing activity, the conventional methods for $\mathrm{C}_{\mathrm{rs}}$ measurement are inaccurate because of the variable muscular pressure of the patient. We hypothesized that a PEEP wave maneuver, analyzed with electrical impedance tomography (EIT), might be suitable for global and regional assessment of $C_{r s}$ during assisted spontaneous breathing.

Methods: After approval of the local ethics committee, we performed a pilot clinical study in 18 mechanically ventilated patients ( $61 \pm 16$ years (mean \pm standard deviation)) who were suitable for weaning with pressure support ventilation (PSV). For the PEEP wave, PEEP was elevated by $1 \mathrm{cmH}_{2} \mathrm{O}$ after every fifth breath during PSV. This was repeated five times, until a total PEEP increase of $5 \mathrm{cmH}_{2} \mathrm{O}$ was reached. Subsequently, PEEP was reduced in steps of $1 \mathrm{cmH}_{2} \mathrm{O}$ in the same manner until the original PEEP level was reached. $\mathrm{C}_{\mathrm{rs}}$ was calculated using EIT from the global, ventral and dorsal lung regions of interest. For reference measurements, all patients were also examined during controlled mechanical ventilation (CMV) with a low-flow pressure-volume maneuver. Global and regional $C_{r s}$ (low-flow) was calculated as the slope of the pressure-volume loop between the pressure that corresponded to the selected PEEP and PEEP $+5 \mathrm{cmH}_{2} \mathrm{O}$. For additional reference, $\mathrm{C}_{\mathrm{rs}}$ during $\mathrm{CMV}\left(\mathrm{C}_{\mathrm{rs}}(\mathrm{CMV})\right)$ was calculated as expired tidal volume divided by the difference between airway plateau pressure and PEEP.

Results: Respiratory system compliance calculated from the PEEP wave ( $C_{r s}$ (PEEP wave)) correlated closely with both reference measurements ( $r=0.79$ for $C_{r s}$ (low-flow) and $r=0.71$ for $C_{r s}(C M V)$ ). No significant difference was observed between the mean $C_{r s}\left(P E E P\right.$ wave) and the mean $C_{r s}(l o w-f l o w)$. However, a significant bias of $+17.1 \mathrm{ml} / \mathrm{cmH}_{2} \mathrm{O}$ was observed between $C_{r s}\left(P E E P\right.$ wave) and $C_{r s}(C M V)$.

Conclusion: Analyzing a PEEP wave maneuver with EIT allows calculation of global and regional $C_{\text {rs }}$ during assisted spontaneous breathing. In mechanically ventilated patients with spontaneous breathing activity, this method might be used for assessment of the global and regional mechanical properties of the respiratory system.
\end{abstract}

\footnotetext{
*Correspondence: tobias.becher@uksh.de

Department of Anesthesiology and Intensive Care Medicine, University

Medical Center Schleswig-Holstein, Campus Kiel, Arnold-Heller-Strasse 3, Haus

12, 24105 Kiel, Germany
} 


\section{Introduction}

Application of positive end-expiratory pressure (PEEP) is an essential part of ventilator therapy for patients with respiratory failure [1-6]. Despite intensive research in the field, the optimal strategy for individual adjustment of PEEP is still under debate. One strategy that may lead to a PEEP setting that maintains lung recruitment without excessive overdistension is to set PEEP $2 \mathrm{cmH}_{2} \mathrm{O}$ above the lower inflection point of a static or quasi-static ("lowflow") pressure-volume loop [7]. This results in ventilation in the area of the pressure-volume loop that is associated with the highest respiratory system compliance $\left(\mathrm{C}_{\mathrm{rs}}\right)$. This approach was part of the lung-protective ventilation strategy successfully applied in two randomized and controlled trials $[2,3]$.

However, the global lower inflection point does not accurately reflect the regional mechanical properties of the respiratory system in acute respiratory distress syndrome (ARDS) [8]. Therefore, to prevent regional alveolar collapse and overdistension, a regional assessment of respiratory system mechanics should be applied. Electrical impedance tomography (EIT) is a non-invasive, radiationfree technique that is suitable for regional measurement of $\mathrm{C}_{\mathrm{rs}}$ [9-12]. Using EIT, regional inflection points can be identified that may be significantly different in the ventral and dorsal parts of the lung [13]. The regional changes in $\mathrm{C}_{\mathrm{rs}}$, determined by EIT, are closely correlated to overdistension and tidal recruitment $[9,10]$. This might be used for the selection of ventilator settings that minimize these deleterious phenomena and are associated with better outcomes [14].

A valid measurement of $C_{r s}$ is a prerequisite for the application of any method that is based on global or regional assessment of respiratory system mechanics. In patients with spontaneous breathing activity, the calculation of $\mathrm{C}_{\mathrm{rs}}$ as the ratio between expired tidal volume $\left(\mathrm{V}_{\mathrm{Te}}\right)$ and the inspiratory driving pressure $(\Delta \mathrm{P})$ becomes inaccurate. Performing a low-flow loop is not feasible in patients when respiratory muscle activity is present. Thus, most conventional $\mathrm{C}_{\mathrm{rs}}$-based methods for PEEP optimization become invalid in the presence of spontaneous breathing activity.

Iotti et al. proposed a method for determination of $\mathrm{C}_{\mathrm{rs}}$ during pressure support ventilation (PSV) using a least squares fit approach. However, their approach requires the pressure support to be set to a very high level, rendering the patient's muscular effort negligible [15]. This could be counterproductive for the weaning process and may not be suitable in patients with high respiratory drive.

A PEEP wave maneuver is an alternative method for the determination of the pressure-volume relationship of the respiratory system. Using this method, $C_{\mathrm{rs}}$ is determined by measuring the PEEP-induced change in endexpiratory lung volume $(\triangle E E L V)$. Originally, this was done by measuring the difference between inspired tidal volume and $\mathrm{V}_{\mathrm{Te}}$ before and after a stepwise increments in PEEP $[16,17]$. Because EIT is able to determine $\triangle E E L V$ regionally $[18,19]$, analyzing the PEEP wave with EIT could provide insight into the regional pressure-volume relationship of the respiratory system. Theoretically, this approach may be suitable for determination of regional $\mathrm{C}_{\mathrm{rs}}$ during assisted mechanical ventilation.

We hypothesized that analyzing a PEEP wave maneuver with EIT could be used for global and regional determination of $\mathrm{C}_{\mathrm{rs}}$ in patients with spontaneous breathing activity.

\section{Materials and methods}

\section{Patients}

We performed a pilot clinical study in the surgical intensive care units (ICUs) of the University Medical Center Schleswig-Holstein, Campus Kiel. Ethical approval was obtained from the ethics committee of the Christian Albrechts University in Kiel, Germany. The study was conducted in compliance with the Helsinki declaration. We included 18 patients ( 5 women and 13 men; age $61 \pm 16$ years (mean \pm standard deviation)) who were endotracheally intubated and mechanically ventilated in the ICU. All patients were already being ventilated with PSV or clinically suitable for ventilation with PSV at the time of inclusion. Exclusion criteria were age $<18$ years, pregnancy, open-chest injury, unstable spinal injury, hemodynamic instability and severe chronic obstructive pulmonary disease. Written informed consent was obtained from all patients or their legal representatives. Detailed patient characteristics are given in Table 1. Additional information on ventilator settings and patient work of breathing is given in Table 2.

\section{Ventilator procedure and data acquisition}

All patients were ventilated with Evita XL ventilators (Dräger Medical, Lübeck, Germany). The examinations were carried out with the patients in the supine or semirecumbent position. The level of pressure support and the initial PEEP were selected according to clinical criteria by the physician in charge, with the aim of achieving a respiratory rate $<30 / \mathrm{min}$ and a tidal volume in the range of 5 to $10 \mathrm{ml} / \mathrm{kg}$ predicted body weight. Airflow and airway pressure $\left(\mathrm{P}_{\mathrm{aw}}\right)$ were recorded from the ventilator at a sampling rate of $125 \mathrm{~Hz}$. Volume was calculated by mathematical integration of the flow signal. Additionally, airflow, $\mathrm{P}_{\mathrm{aw}}$ and esophageal pressure $\left(\mathrm{P}_{\mathrm{es}}\right)$ were recorded with the BiCore 2 measurement device (CareFusion, Yorba Linda, CA, USA) at a sampling rate of $100 \mathrm{~Hz}$. Correct positioning of the esophageal probe was confirmed by visual analysis of cardiac oscillations and by performing an end-expiratory occlusion test as described by Baydur et al. [21].

EIT data were acquired using the Goe-MF II device (CareFusion). Sixteen self-adhesive electrodes (Blue Sensor L-00-S; Ambu, Ballerup, Denmark) were placed around the 
Table 1 Patients' characteristics

\begin{tabular}{|c|c|c|c|c|}
\hline Patient & $\begin{array}{l}\text { Height } \\
\text { (cm) }\end{array}$ & $\begin{array}{l}\text { Airway } \\
\text { (ETT/TT; mm ID) }\end{array}$ & $\begin{array}{l}\text { MV duration } \\
\text { (days) }\end{array}$ & Diagnosis \\
\hline 1 & 180 & ETT; 8.0 & 12 & ARDS (moderate) \\
\hline 2 & 168 & ETT; 7.5 & 4 & Sepsis \\
\hline 3 & 175 & ТТ; 9.0 & 22 & ARDS (mild) \\
\hline 4 & 158 & ETT; 7.0 & 9 & ARDS (moderate) \\
\hline 5 & 185 & ETT; 8.0 & 8 & ARDS (moderate) \\
\hline 6 & 170 & ETT; 8.5 & 4 & ARDS (moderate) \\
\hline 7 & 170 & ETT; 8.0 & 6 & ARDS (moderate) \\
\hline 8 & 166 & $\mathrm{ETT} ; 8.0$ & 6 & ARDS (moderate) \\
\hline 9 & 160 & ETT; 7.5 & 1 & ARDS (mild) \\
\hline 10 & 164 & ETT; 8.5 & 1 & Postop. \\
\hline 11 & 171 & ETT; 7.5 & 7 & Sepsis \\
\hline 12 & 179 & Tा; 9.0 & 24 & ARDS (mild) \\
\hline 13 & 176 & ETT; 8.5 & 1 & Postop. \\
\hline 14 & 166 & ETT; 7.5 & 5 & Cardiac failure \\
\hline 15 & 163 & Tा; 9.0 & 15 & ARDS (moderate) \\
\hline 16 & 178 & ETT; 8.5 & 1 & Postop. \\
\hline 17 & 182 & Tा; 9.0 & 5 & ARDS (moderate) \\
\hline 18 & 170 & ETT; 8.5 & 7 & ARDS (mild) \\
\hline Mean & 171 & - & 8 & - \\
\hline SD & 8 & - & 7 & - \\
\hline
\end{tabular}

Acute respiratory distress syndrome (ARDS) severity was assessed according to the Berlin definition [20]. ETT: Endotracheal tube; TT: Tracheostomy tube; ID: Inner diameter; MV duration: Days of mechanical ventilation prior to the study, with the day of study procedure included; Postop.: Patients without pulmonary pathology examined after scheduled major surgery.

chest circumference in one transverse plane lying approximately at the level of the fifth intercostal space. EIT images were obtained at a scan rate of $25 \mathrm{~Hz}$.

\section{Controlled mechanical ventilation}

To obtain reference values for $\mathrm{C}_{\mathrm{rs}}$, all patients were deeply sedated to a score of -5 on the Richmond Agitation and Sedation Scale (RASS) [22]. If spontaneous breathing activity (as evidenced by careful observation of the flow, $\mathrm{P}_{\mathrm{aw}}$ and $\mathrm{P}_{\mathrm{es}}$ curves) persisted at a RASS score of -5 , patients were additionally paralyzed with rocuronium bromide in order to temporarily interrupt all spontaneous breathing activity. At the same time, the ventilator mode was changed from PSV to CMV. During CMV, patients were ventilated with a $\mathrm{V}_{\mathrm{Te}}$ of $8 \pm 2 \mathrm{ml} / \mathrm{kg}$ predicted body weight. Inspiratory flow was adjusted to reach an endinspiratory pause $\left(\mathrm{T}_{\mathrm{plat}}\right)$ of $0.8 \pm 0.3$ seconds. Airway plateau pressure $\left(\mathrm{P}_{\text {plat }}\right)$ was measured at the end of $\mathrm{T}_{\text {plat }}$. After a short phase of CMV, a low-flow pressure-volume maneuver was performed by the ventilator with a constant gas flow of $4 \mathrm{~L} / \mathrm{min}$, starting at $0 \mathrm{P}_{\mathrm{aw}}$ up to a maximum volume of $2 \mathrm{~L}$ or a maximum $\mathrm{P}_{\mathrm{aw}}$ of $35 \mathrm{cmH}_{2} \mathrm{O}$. After this maneuver, patients were ventilated with $\mathrm{CMV}$ until the effects of the applied sedatives and (if applicable) neuromuscular blocking agents had subsided. After the return of sufficient spontaneous breathing activity, the ventilator mode was changed back to PSV with the previous settings. The PEEP level remained unchanged when the ventilator modes were switched from PSV to CMV and vice versa.

\section{PEEP wave maneuver}

The PEEP wave maneuver was executed during PSV in a phase of stable spontaneous breathing. The flow trigger was set to $2 \mathrm{~L} / \mathrm{min}$, and the PS termination criterion was adjusted to $25 \%$ of peak inspiratory flow. The dosing of sedatives was adjusted to achieve a RASS score of -3 to -4 . For the maneuver, the PEEP level was elevated by $1 \mathrm{cmH}_{2} \mathrm{O}$ after five consecutive PSV breaths at the initial PEEP level. After another five breaths, PEEP was elevated by another $1 \mathrm{cmH}_{2} \mathrm{O}$. This procedure was repeated five times until a total PEEP increase of $5 \mathrm{cmH}_{2} \mathrm{O}$ compared to the initial value was achieved. Afterward, PEEP was lowered in increments of $1 \mathrm{cmH}_{2} \mathrm{O}$ in the same way (Figure 1).

\section{Sequence of measurements}

The sequence of measurements was defined randomly. In nine patients, we performed the PEEP wave before the reference measurements; in the other nine patients, the reference measurements were performed before the PEEP wave.

\section{Electrical impedance tomography image generation and analysis}

Cross-sectional images were calculated from EIT data using a normalized difference reconstruction algorithm based on the Graz consensus reconstruction algorithm for EIT [23]. To minimize artifacts caused by cardiac oscillations, a low-pass filter with a cutoff frequency set at $50 \mathrm{~Hz}$, which in all cases was below the patients' heart rates, was employed. A functional region of interest (ROI) was selected individually for every patient using the regression slope method [24] on the EIT data that had been recorded during the PEEP wave. For regional analysis, the ROI was divided into a ventral part and a dorsal part along a horizontal line. This line was placed exactly in the middle of the vertical lung region dimension (Figure 2) by dividing the total number of horizontal rows of EIT data in the ROI by 2 . In cases of an uneven number of rows, the remaining row was added to the dorsal part of the ROI. Once the functional lung ROI had been defined for an individual patient using the EIT images generated during the PEEP wave maneuver, the same ROI was applied for all further analyses of the PEEP wave and the reference measurements in CMV. 
Table 2 Ventilator settings

\begin{tabular}{|c|c|c|c|c|c|c|c|c|}
\hline Patient & $\mathrm{RR}_{\mathrm{CMV}}(1 / \mathrm{min})$ & $\mathrm{V}_{\mathrm{T}, \mathrm{CMV}}(\mathrm{ml})$ & $\mathrm{P}_{\text {plat }, \mathrm{CMV}}\left(\mathrm{cmH}_{2} \mathrm{O}\right)$ & PEEP $\left(\mathrm{cmH}_{2} \mathrm{O}\right)$ & $\mathrm{RR}_{\mathrm{PSV}}(1 / \mathrm{min})$ & $\mathrm{V}_{\mathrm{T}, \mathrm{PSV}}(\mathrm{ml})$ & $\mathrm{PS}\left(\mathrm{cmH}_{2} \mathrm{O}\right)$ & WOB $(\mathrm{J} / \mathrm{L})$ \\
\hline 1 & 15 & 550 & 23 & 10 & 14 & 510 & 10 & 0.35 \\
\hline 2 & 16 & 520 & 24 & 10 & 16 & 530 & 12 & 0.96 \\
\hline 3 & 35 & 300 & 35 & 10 & 15 & 440 & 10 & 1.23 \\
\hline 4 & 27 & 270 & 36 & 15 & 18 & 400 & 15 & 0.91 \\
\hline 5 & 14 & 540 & 20 & 10 & 13 & 660 & 10 & 0.46 \\
\hline 6 & 10 & 710 & 30 & 12 & 16 & 670 & 13 & 0.98 \\
\hline 7 & 18 & 510 & 24 & 15 & 16 & 540 & 10 & 0.93 \\
\hline 8 & 13 & 500 & 29 & 15 & 17 & 460 & 9 & 0.48 \\
\hline 9 & 13 & 510 & 23 & 11 & 18 & 510 & 8 & 1.02 \\
\hline 10 & 12 & 520 & 12 & 5 & 17 & 690 & 6 & 0.19 \\
\hline 11 & 15 & 550 & 16 & 5 & 16 & 820 & 7 & 0.84 \\
\hline 12 & 20 & 490 & 19 & 7 & 14 & 500 & 12 & 0.58 \\
\hline 13 & 22 & 540 & 25 & 15 & 15 & 750 & 10 & 0.53 \\
\hline 14 & 15 & 480 & 22 & 8 & 17 & 600 & 12 & 1.11 \\
\hline 15 & 15 & 390 & 33 & 13 & 17 & 620 & 12 & 0.84 \\
\hline 16 & 10 & 640 & 21 & 10 & 14 & 400 & 9 & 0.48 \\
\hline 17 & 18 & 420 & 20 & 12 & 14 & 920 & 8 & 0.42 \\
\hline 18 & 13 & 600 & 19 & 8 & 16 & 480 & 10 & 0.59 \\
\hline Mean & 17 & 501 & 24 & 11 & 16 & 585 & 10 & 0.72 \\
\hline SD & 6 & 104 & 6 & 3 & 1 & 131 & 2 & 0.29 \\
\hline
\end{tabular}

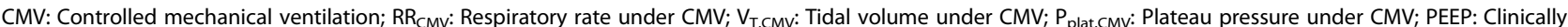
selected positive end-expiratory pressure; $R_{P S V}$ : Respiratory rate under pressure support ventilation (before the start of the PEEP wave maneuver); $V_{T, P S V}$ : Mean tidal volume during pressure support ventilation before the start of the PEEP wave maneuver; PS: Pressure support during PSV; WOB: Patient work of breathing during undisturbed PSV.

\section{Calculation of respiratory system compliance from positive end-expiratory pressure wave}

To obtain a calibration factor between tidal impedance change $(\Delta \mathrm{Z})$ and $\mathrm{V}_{\mathrm{Te}}$, the mean $\mathrm{V}_{\mathrm{Te}}$ during 4 breaths at the initial PEEP level was divided by the mean global tidal $\Delta \mathrm{Z}$ during the same breaths. To obtain the relationship between PEEP and $\triangle Z$, the slope of the mean change in global impedance minima per $\mathrm{cmH}_{2} \mathrm{O}$ during the PEEP wave was calculated using a least-squares approximation (Figure 3). The obtained slope was then multiplied with the aforementioned calibration factor to calculate the global value of $\mathrm{C}_{\mathrm{rs}}$ (PEEP wave) in $\mathrm{ml} / \mathrm{cmH}_{2} \mathrm{O}$.

For regional analysis of $\mathrm{C}_{\mathrm{rs}}$ during the PEEP wave, the slopes of the mean change in impedance minima were calculated separately for the ventral and dorsal lung ROIs. The respective values were then multiplied by the global calibration factor to obtain the regional values of $C_{\mathrm{rs}}$ (PEEP wave $)_{\text {ventral }}$ and $\mathrm{C}_{\mathrm{rs}}(\text { PEEP wave })_{\text {dorsal }}$. Because the ventral and dorsal parts of the functional lung ROI may contain a different number of image pixels, normalized regional per-pixel values of $\mathrm{C}_{\mathrm{rs}}$ (PEEP wave) were calculated by dividing $\mathrm{C}_{\mathrm{rs}}(\text { PEEP wave })_{\text {ventral }}$ and $\mathrm{C}_{\mathrm{rs}}(\text { PEEP wave })_{\text {dorsal }}$ by the total number of image pixels in the respective parts of the ROI.

\section{Calculation of reference values for respiratory system compliance}

To obtain a reference value for quasi-static $C_{r s}$, we calculated the slope of the low-flow pressure-volume loop between the $\mathrm{P}_{\mathrm{aw}}$ values spanning the PEEP settings during the PEEP wave maneuver. For example, if the PEEP wave had started at a PEEP of $15 \mathrm{cmH}_{2} \mathrm{O}$ in an individual patient, the slope of the low-flow pressure-volume loop was calculated between $\mathrm{P}_{\mathrm{aw}}$ of $15 \mathrm{cmH}_{2} \mathrm{O}$ and 20 $\mathrm{cmH}_{2} \mathrm{O}$ to obtain the reference value of $\mathrm{C}_{\mathrm{rs}}$ (low-flow) (Figure 4A).

To obtain reference values of ventral and dorsal $C_{r s}$, the slopes of the mean changes in ventral, dorsal and global impedance minima per $1 \mathrm{cmH}_{2} \mathrm{O} \mathrm{P}$ aw were calculated from the same sections of the low-flow loops (Figure 4B). The ventral and dorsal fractions of $\mathrm{C}_{\mathrm{rs}}$ were then calculated by dividing the respective slope values by the global slope. $\mathrm{C}_{\mathrm{rs}}(\text { low-flow })_{\text {ventral }}$ and $\mathrm{C}_{\mathrm{rs}}$ (low-flow) dorsal were then obtained by multiplying the fractional ventral and dorsal slopes by the global $\mathrm{C}_{\mathrm{rs}}$ (low-flow). The regional per-pixel values of $\mathrm{C}_{\mathrm{rs}}$ (low-flow) were calculated by dividing the ventral and dorsal values by the total number of image pixels in the respective parts of the ROI. 

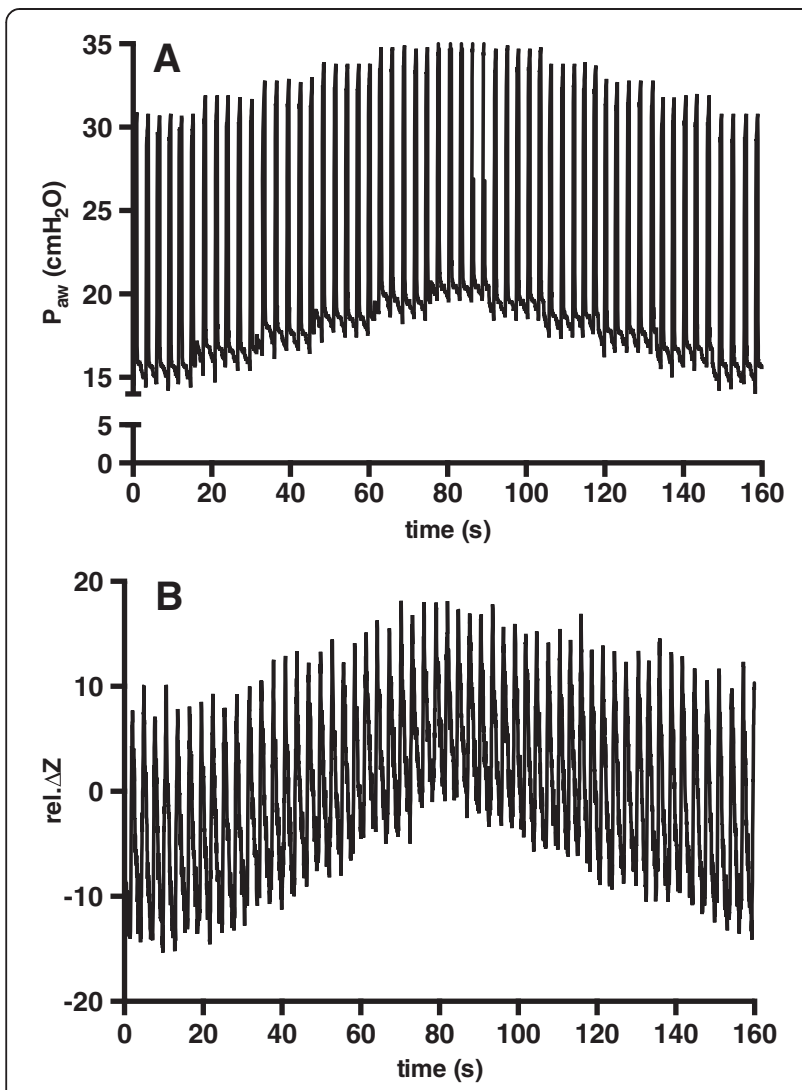

Figure 1 Airway pressure and electrical impedance tomography waveforms acquired during the positive end-expiratory pressure wave maneuver in one of the studied patients. (A) Airway pressure $\left(P_{\text {aw }}\right)$ during the maneuver. Positive end-expiratory pressure was elevated by $1 \mathrm{cmH}_{2} \mathrm{O}$ after every fifth breath while the pressure support level remained constant. (B) Time course of global relative impedance changes (rel. $\Delta Z$ ) during the maneuver.

For additional reference, $\mathrm{C}_{\mathrm{rs}}$ during controlled mechanical ventilation $\left(\mathrm{C}_{\mathrm{rs}}(\mathrm{CMV})\right)$ was calculated as $\mathrm{V}_{\mathrm{Te}}$ divided by the difference between $\mathrm{P}_{\text {plat }}$ and PEEP:

$$
\mathrm{C}_{\mathrm{rs}}(\mathrm{CMV})=\mathrm{V}_{\mathrm{Te}} /\left(\mathrm{P}_{\text {plat }}-\mathrm{PEEP}\right)
$$

\section{Statistical analysis}

All data were tested for normal distribution using the D'Agostino-Pearson omnibus normality test with a threshold $\alpha=0.05$. The interpatient correlations between $C_{\mathrm{rs}}$ assessed with the PEEP wave maneuver and the reference values for $C_{\mathrm{rs}}$ were calculated with the Pearson correlation for normally distributed data and with the Spearman correlation for non-normally distributed data. Additionally, all data were compared with the BlandAltman analysis. The differences between the mean results of the methods were tested for statistical significance using a paired $t$-test.

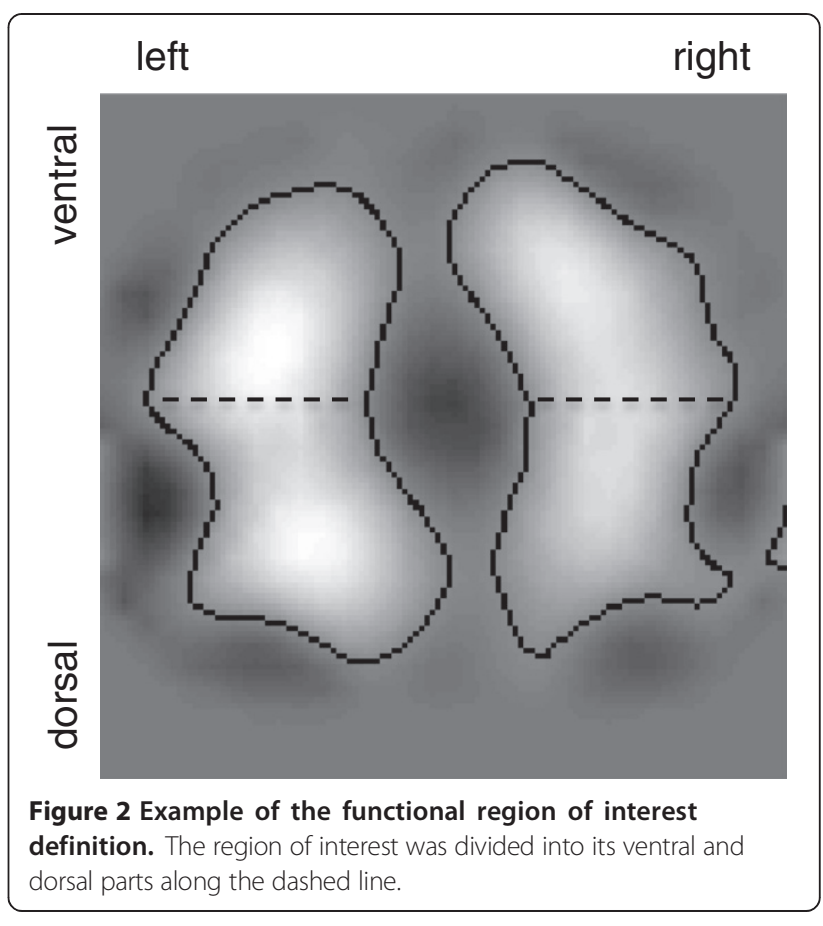

\section{Results}

All analyzed data passed the normality test. Thus, the Pearson correlation could be calculated for all data sets analyzed.

The mean values and standard deviations of $\mathrm{C}_{\mathrm{r}}$, assessed with the different methods, are presented in Table 3. Individual $C_{\mathrm{rs}}$ values are provided in Table $\mathrm{S} 1$ and Table $\mathrm{S} 2$ in Additional file 1. An overview of all correlations, bias and limits of agreement is given in Table S3 in Additional file 1.

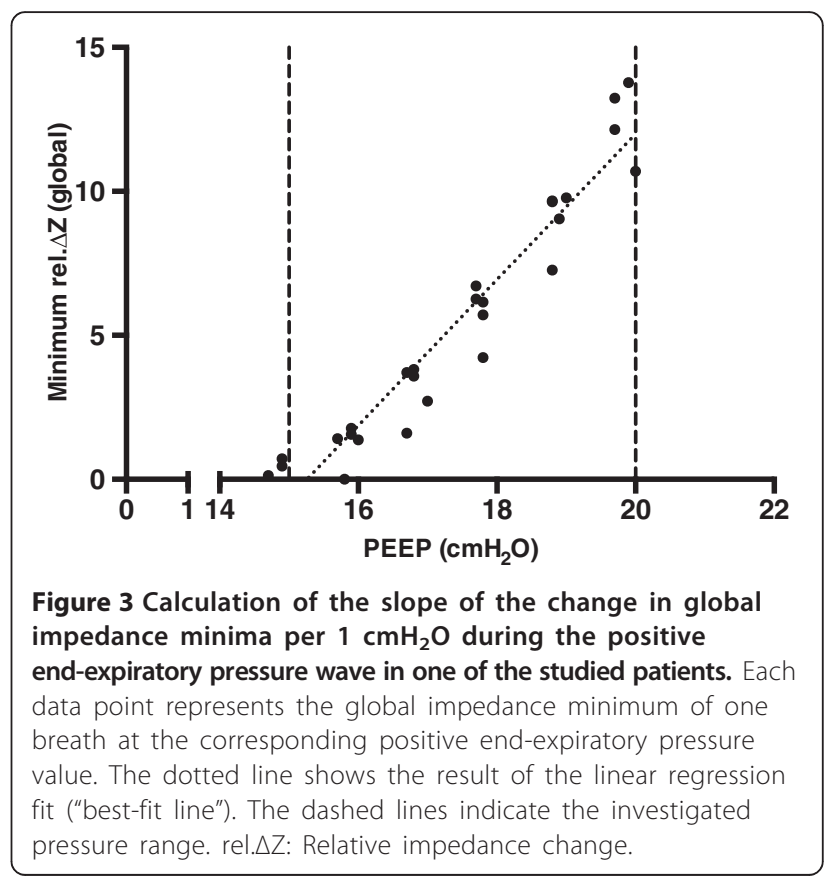



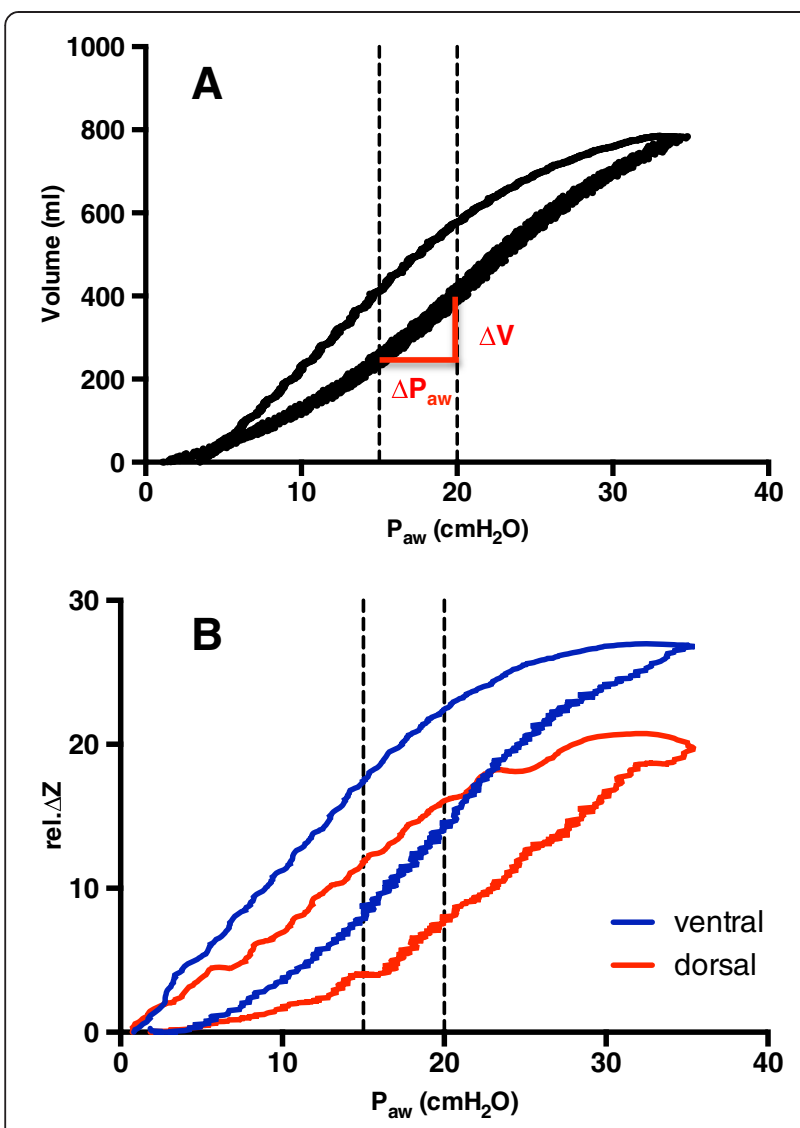

Figure 4 Low-flow pressure-volume loop. (A) Example of a global low-flow pressure-volume loop in one of the studied patients. The slope of global volume change $(\Delta V$ ) divided by the corresponding change in airway pressure $\left(\Delta \mathrm{P}_{\mathrm{aw}}\right)$ was calculated in the pressure range that was examined with the positive end-expiratory pressure (PEEP) wave, providing a reference value for global respiratory system compliance $\left(\mathrm{C}_{\mathrm{rs}}(\mathrm{low}\right.$-flow)). The dashed lines indicate the pressure range investigated during the PEEP wave maneuver. (B) Regional pressure-impedance (rel. $\Delta$ Z) loops obtained by electrical impedance tomography during the same maneuver. The slopes of the curves obtained in the ventral and dorsal lung regions were multiplied by $C_{r s}$ (low-flow) to yield the reference values of $C_{r s}$ (low-flow) ventral and $C_{r s}$ (low-flow) dorsal, respectively. The dotted lines indicate the investigated pressure range (PEEP - PEEP +5).

\section{Global respiratory system compliance}

Comparing $C_{\mathrm{rs}}$ (PEEP wave) to the reference values, we found a highly significant correlation with the reference value $C_{\mathrm{rs}}$ (low-flow) $\left(r=0.80 ; P<0.0001 ; \mathrm{C}_{\mathrm{rs}}\right.$ (PEEP wave $)=$ $0.73 \times \mathrm{C}_{\mathrm{rs}}($ low-flow $\left.)+21\right)$. There was a clear trend $(P=0.06)$ toward a higher mean $\mathrm{C}_{\mathrm{rs}}$ (PEEP wave) of $6.8 \mathrm{ml} / \mathrm{cmH}_{2} \mathrm{O}$ in comparison to $\mathrm{C}_{\mathrm{rs}}$ (low-flow).

In comparison to the second reference value, $C_{r s}$ (CMV), we found a similar degree of correlation that was also highly significant $\left(r=0.71 ; P=0.001 ; \mathrm{C}_{\mathrm{rs}}(\mathrm{PEEP}\right.$ wave $\left.=0.91 \times \mathrm{C}_{\mathrm{rs}}(\mathrm{CMV})+21\right)$. The mean $\mathrm{C}_{\mathrm{rs}}($ PEEP wave $)$ was $+17.1 \mathrm{ml} / \mathrm{cmH}_{2} \mathrm{O}$ higher than the mean $\mathrm{C}_{\mathrm{rs}}(\mathrm{CMV})$. This difference was statistically significant $(P=0.0002)$.
Table 3 Means and standard deviations of the analyzed values of respiratory system compliance

\begin{tabular}{|c|c|}
\hline Value & Mean \pm SD $\left(\mathrm{ml}^{2} \mathrm{cmH}_{2} \mathrm{O}\right)$ \\
\hline$\overline{C_{\mathrm{rs}}(\text { PEEP wave) }}$ & $59.8 \pm 20.8$ \\
\hline$C_{r s}(\text { PEEP wave })_{\text {ventral }}$ & $40.9 \pm 15.9$ \\
\hline$C_{r s}(\text { PEEP wave })_{\text {dorsal }}$ & $18.8 \pm 9.3^{a}$ \\
\hline$C_{r s}($ PEEP wave) per pixel & $0.20 \pm 0.09$ \\
\hline$C_{r s}(\text { PEEP wave })_{\text {ventral }}$ per pixel & $0.26 \pm 0.13$ \\
\hline$C_{r s}(\text { PEEP wave })_{\text {dorsal }}$ per pixel & $0.14 \pm 0.07^{b}$ \\
\hline$C_{r s}($ low-flow $)$ & $53.0 \pm 22.4$ \\
\hline$C_{r s}(l o w-f l o w)_{\text {ventral }}$ & $36.2 \pm 16.5$ \\
\hline$C_{r s}(\text { low-flow })_{\text {dorsal }}$ & $16.8 \pm 8.8^{a}$ \\
\hline$C_{r s}($ low-flow) per pixel & $0.18 \pm 0.07$ \\
\hline$C_{r s}(l o w-f l o w)_{\text {ventral }}$ per pixel & $0.23 \pm 0.11$ \\
\hline$C_{r s}(l o w-f l o w)_{\text {dorsal }}$ per pixel & $0.12 \pm 0.06^{\mathrm{a}}$ \\
\hline $\mathrm{C}_{\mathrm{rs}}(\mathrm{CMV})$ & $47.1 \pm 21.6$ \\
\hline
\end{tabular}

${ }^{a}$ Significantly different from the corresponding value in the ventral region $(P<0.0001)$. ${ }^{b}$ Significantly different from the corresponding value in the ventral region $(P=0.0002)$. Per-pixel values were obtained by dividing the ventral and dorsal values of $C_{r s}$ by the total number of image pixels in the respective regions of interest. $C_{r s}$ (PEEP wave): Respiratory system compliance obtained by performing the positive end-expiratory pressure (PEEP) wave maneuver during pressure support ventilation; $C_{r s}$ (low-flow): Quasi-static $C_{r s}$ obtained with the low-flow loop during controlled mechanical ventilation; $C_{r s}$ $(\mathrm{CMV}): \mathrm{C}_{\mathrm{rs}}$ calculated by dividing expiratory tidal volume by the difference between plateau airway pressure and PEEP during controlled mechanical ventilation.

The correlation and the Bland-Altman methods comparison of $\mathrm{C}_{\mathrm{rs}}$ (PEEP wave) with both reference values are shown in Figure 5.

\section{Regional respiratory system compliance}

The ventral $\mathrm{C}_{\mathrm{rs}}$ (PEEP wave) was significantly correlated to the ventral $C_{\mathrm{rs}}$ (low-flow) $(r=0.77 ; P=0.0002)$. Similar to the global results, there was a trend toward a higher value of ventral $C_{\mathrm{rs}}$ (PEEP wave) in comparison with ventral $\mathrm{C}_{\mathrm{rs}}$ (low-flow) that did not reach statistical significance. The correlation of the dorsal $C_{\mathrm{rs}}$ (PEEP wave) with the dorsal $\mathrm{C}_{\mathrm{rs}}$ (low-flow) was weaker than the correlation in the ventral ROIs, but still highly significant $(r=0.65 ; P=0.003)$. Again, there was a trend toward a higher value of $C_{\mathrm{rs}}$ (PEEP wave) in comparison to $\mathrm{C}_{\mathrm{rs}}$ (low-flow) that did not reach statistical significance $(P=0.24)$. The regional correlations and Bland-Altman comparisons are shown in Figure 6.

Both the ventral $\mathrm{C}_{\mathrm{rs}}$ (low-flow) and $\mathrm{C}_{\mathrm{rs}}$ (PEEP-wave) values were significantly higher than the corresponding dorsal values $(P<0.0001)$. When comparing the normalized per-pixel values, the ventral $C_{r s}$ (low-flow) and $C_{r s}$ (PEEP wave) values were still significantly higher than their dorsal equivalents $(P=0.0002$ and $P<0.0001$, respectively). The correlations of the per-pixel $C_{r s}$ values and the Bland-Altman comparisons are depicted in Figure 7. 

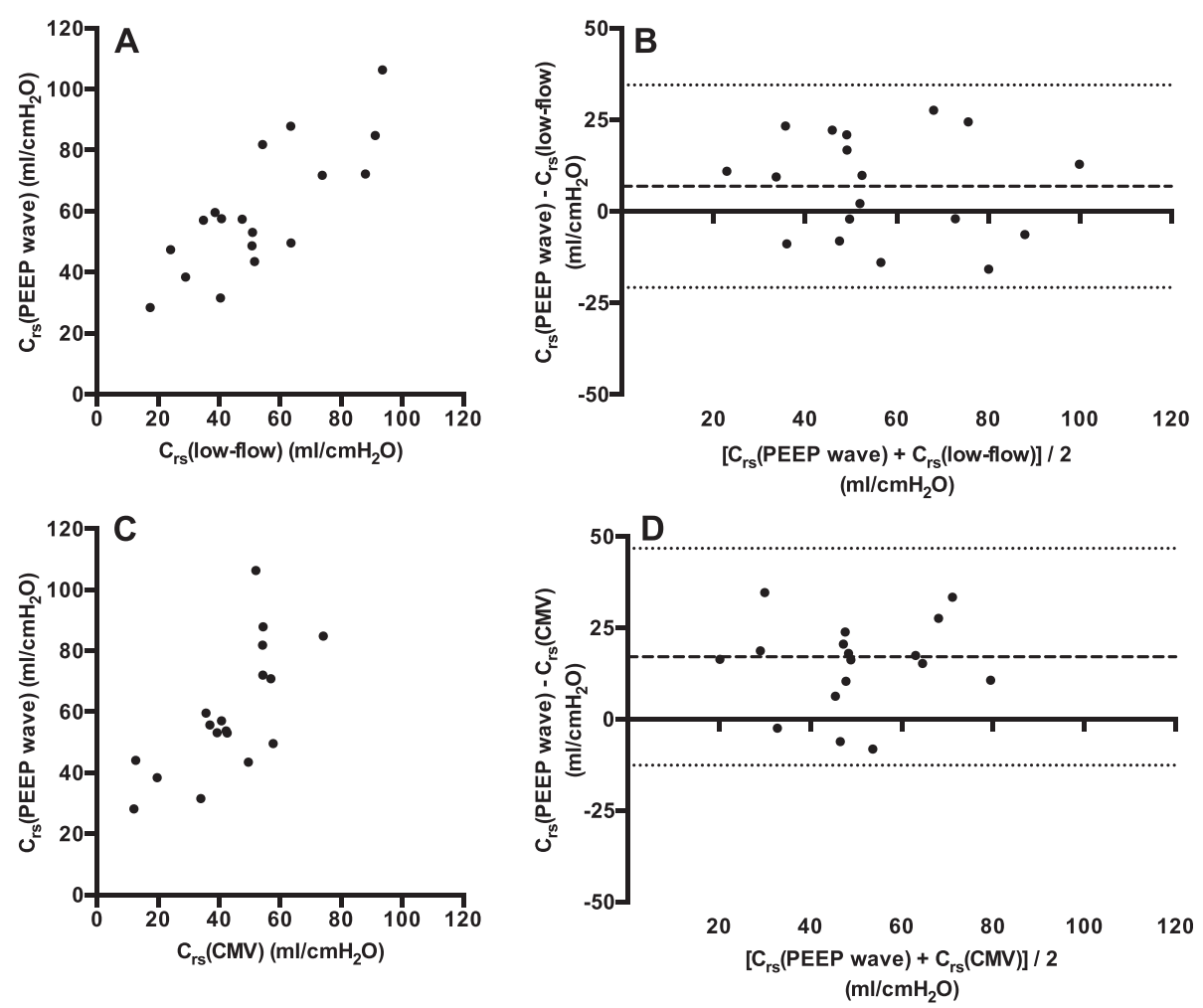

Figure $\mathbf{5}$ Comparison of global values for respiratory system compliance. (A) Correlation between the global respiratory system compliance $\left(C_{r s}\right)$, determined with electrical impedance tomography during assisted spontaneous breathing with the (PEEP) wave maneuver $\left(C_{r s}(P E E P\right.$ wave)), and quasi-static $C_{r s}$, determined in the passive patient with a low-flow pressure-volume loop ( $C_{r s}$ (low-flow). (B) Bland-Altman method comparison between $C_{r s}(P E E P$ wave $)$ and $C_{r s}\left(\right.$ low-flow). The dashed line indicates the bias $\left(+6.8 \mathrm{ml} / \mathrm{cmH}_{2} \mathrm{O}\right)$, and the dotted lines indicate the $95 \%$ limits of agreement ( -20.8 to $+34.5 \mathrm{ml} / \mathrm{cmH}_{2} \mathrm{O}$ ). (C) Correlation between $\mathrm{C}_{\mathrm{rs}}$ (PEEP wave) and $\mathrm{C}_{\mathrm{rs}}$ determined during volume-controlled ventilation $\left(\mathrm{C}_{\mathrm{rs}}(\mathrm{CMV})\right.$ ). (D) Bland-Altman method comparison between $\mathrm{C}_{\mathrm{rs}}\left(\mathrm{PEEP}\right.$ wave) and $\mathrm{C}_{\mathrm{rs}}(\mathrm{CMV})$. The dashed line indicates the bias $\left(+17.1 \mathrm{ml} / \mathrm{cmH}_{2} \mathrm{O}\right)$, and the dotted lines indicate the $95 \%$ limits of agreement $\left(-13\right.$ to $\left.+47 \mathrm{ml} / \mathrm{cmH}_{2} \mathrm{O}\right)$.
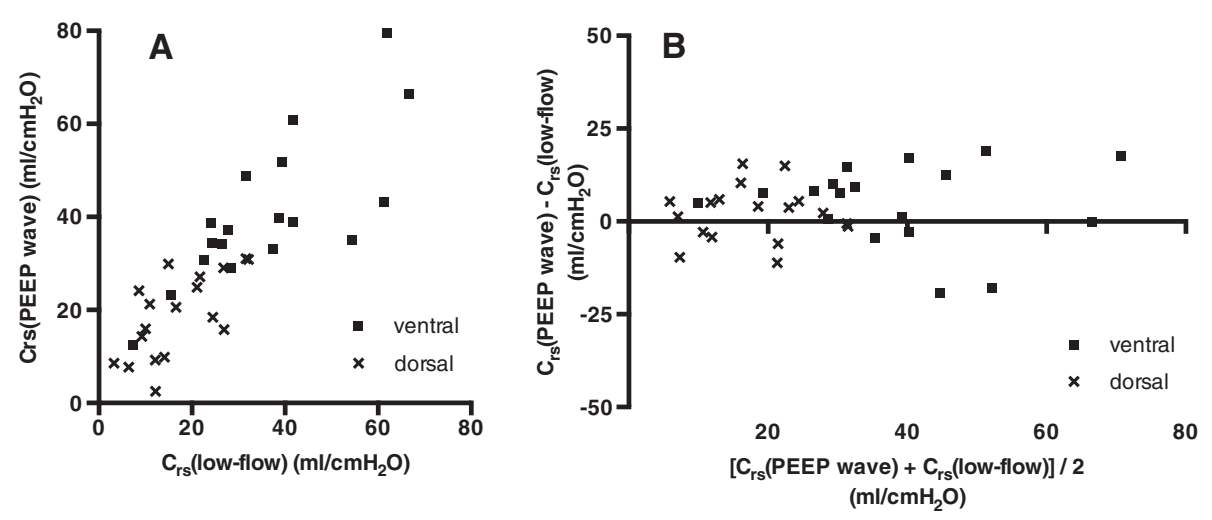

Figure 6 Comparison of regional values for respiratory system compliance. (A) Correlation between regional respiratory system compliance $\left(C_{r s}\right)$, determined using electrical impedance tomography $(E I T)$ during assisted spontaneous breathing with the positive end-expiratory pressure (PEEP) wave maneuver ( $C_{r s}$ (PEEP wave) and quasi-static regional $C_{r s}$ determined in the passive patient with EIT during a low-flow pressure-volume loop $\left(C_{r s}\left(\right.\right.$ low-flow)). (B) Bland-Altman method comparison between regional $C_{r s}\left(P E E P\right.$ wave) and regional $C_{r s}$ (low-flow). 

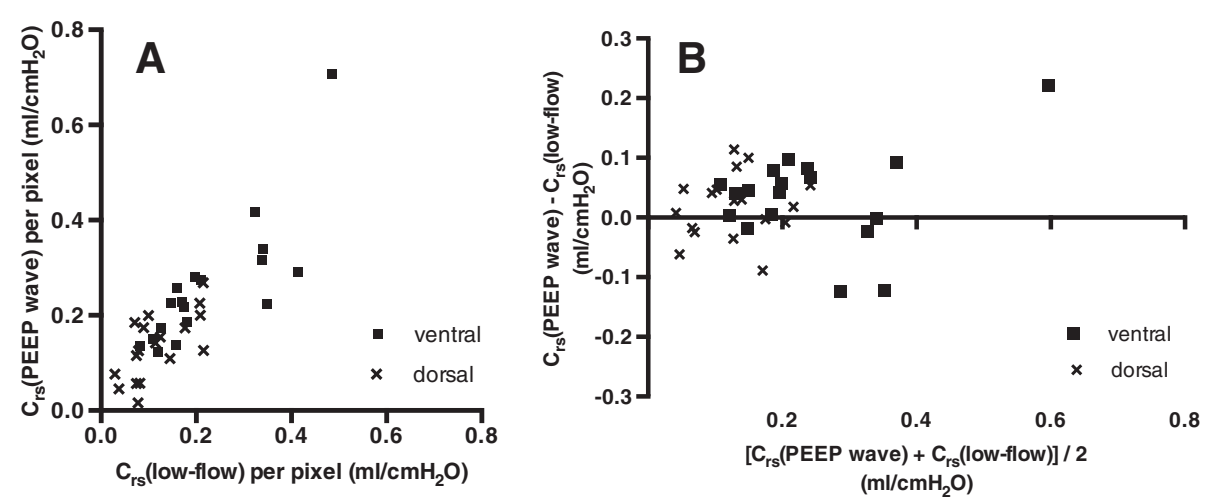

Figure 7 Comparison of regional per-pixel values for respiratory system compliance. (A) Correlation between the regional respiratory system compliance $\left(C_{r s}\right)$, determined with electrical impedance tomography during assisted spontaneous breathing with the positive end-expiratory pressure (PEEP) wave maneuver $\left(C_{r s}(P E E P\right.$ wave $)$ ) and quasi-static regional $C_{r s}$ determined in the passive patient with a low-flow pressure-volume loop $\left(C_{r s}(l o w-f l o w)\right)$, after normalizing the regional values to the number of pixels in the ventral and dorsal regions of interest for every patient. (B) Bland-Altman method comparison between the regional values, normalized to the number of pixels in the respective regions.

\section{Discussion}

We performed a pilot clinical study to determine global and regional $\mathrm{C}_{\mathrm{rs}}$ by performing a PEEP wave maneuver during PSV that was subsequently analyzed with EIT. The calculated values were compared to reference values that had been determined with a low-flow pressurevolume maneuver and during volume-controlled ventilation with $\mathrm{T}_{\text {plat }}$. We found highly significant correlations between $C_{\mathrm{rs}}$ (PEEP wave) and the values obtained using the reference methods. However, there was a trend toward a higher mean $C_{r s}$ (PEEP wave) compared to the reference $C_{r s}$ values. This difference did not reach statistical significance when we compared $C_{\mathrm{rs}}$ (PEEP wave) to the quasi-static $\mathrm{C}_{\mathrm{rs}}$ (low-flow), which may have been due to our relatively small sample size; however, it was highly significant when we compared $\mathrm{C}_{\mathrm{rs}}$ (PEEP wave) to $\mathrm{C}_{\mathrm{rs}}(\mathrm{CMV})$.

\section{Measurement bias}

There are several possible explanations for the higher mean value of $C_{r s}$ (PEEP wave) compared to the reference values. First, owing to the long equilibration time at every PEEP level, assessment of $\mathrm{C}_{\mathrm{rs}}$ during a PEEP wave maneuver yields an almost static value. Because the reference value $C_{\mathrm{rs}}(\mathrm{CMV})$ was calculated by dividing $\mathrm{V}_{\mathrm{Te}}$ by the difference between $\mathrm{P}_{\text {plat }}$ measured after an end-inspiratory occlusion of only $0.8 \pm 0.3$ seconds, it was likely to be lower than the "static" $C_{\mathrm{rs}}$ (PEEP wave) due to the viscoelastic properties of the patient's respiratory system [25]. Moreover, especially in patients with ARDS, $\mathrm{C}_{\mathrm{rs}}$ is usually nonlinear and tends to be lower at higher levels of airway pressure [26]. Because the values of $\mathrm{P}_{\text {plat }}$ were obviously much higher than the pressure range we investigated with our PEEP wave maneuver, this effect is likely to have contributed to the difference between $\mathrm{C}_{\mathrm{rs}}$ (PEEP wave) and $\mathrm{C}_{\mathrm{rs}}(\mathrm{CMV})$.
Another explanation for the observed differences could be the fact that spontaneous breathing may lead to recruitment of lung tissue and to alterations of chest wall mechanics [27]. This could have contributed to the higher $\mathrm{C}_{\mathrm{rs}}$ we found with the PEEP wave during assisted spontaneous breathing. Additionally, the PEEP wave itself could also cause recruitment by an increase in mean and peak airway pressures during the maneuver.

The observed global increase in impedance may in part have been caused by a displacement of blood out of the thorax resulting from the change in mean airway pressure. Such an effect would lead to an increase in global impedance within the lung ROI that cannot easily be distinguished from an increase caused by rising EELV. However, because the displacement of blood is accompanied by a simultaneous increase in aerated lung volume, the absolute change in impedance due to changes in blood volume may be negligible as compared to the concomitant changes in aerated lung volume [28].

\section{Accuracy of the proposed method}

Although we found a good general correlation between $\mathrm{C}_{\mathrm{rs}}$ (PEEP wave) and the reference values, considerable differences were observed between these values in some patients. Also, the overall 95\% limits of agreement were relatively broad when we compared $C_{r s}$ (PEEP wave) to the reference measurements. This may in part be caused by alterations in respiratory system mechanics induced by spontaneous breathing. Additionally, one must bear in mind that the PEEP wave maneuver during PSV is based on the assumption that that patient's respiratory muscles reach a more or less relaxed state at the end of expiration. In patients who exhibit an irregular breathing pattern or who use their expiratory muscles actively to counterbalance the effects of PEEP, the measurement of $\mathrm{C}_{\mathrm{rs}}$ with a PEEP wave may become inaccurate. For our 
study, the PEEP wave maneuver was executed during a relatively deep level of sedation (RASS -3 to -4 ) in order to achieve a state of relaxed spontaneous breathing. However, because there were no predefined exclusion criteria related to the patient's breathing pattern, expiratory muscle activity or irregular breathing patterns may still have been present in some of our patients.

For broad application of the proposed method during PSV, it might be necessary to define exclusion criteria based on the patient's breathing pattern in order to avoid faulty measurements. It should then be possible to test the proposed method in patients under lighter sedation.

\section{Regional analysis}

In our regional analysis, we found a significantly higher $\mathrm{C}_{\mathrm{rs}}$ (PEEP wave) as well as $\mathrm{C}_{\mathrm{rs}}$ (low flow) in the ventral ROI when compared to the dorsal ROI. Because the ROIs were divided along a horizontal line in the middle of their vertical dimensions, this may have resulted in a different number of pixels in the ventral and dorsal ROIs. In fact, there were slightly more image pixels in the ventral part of the ROI $(166 \pm 44$ (mean \pm SD) ventral vs. $143 \pm 23$ dorsal; $P=0.02$ ). However, after normalizing the regional $\mathrm{C}_{\mathrm{rs}}$ to the number of pixels in the respective parts of the ROI, there was still a significantly higher $C_{\mathrm{rs}}$ in the ventral part, when assessed with the PEEP wave and with the low-flow loop. Therefore, the differences between ventral and dorsal $C_{\mathrm{rs}}$ cannot be explained by the number of pixels alone.

A likely explanation for the higher ventral values of $\mathrm{C}_{\mathrm{rs}}$ (PEEP wave) and $\mathrm{C}_{\mathrm{rs}}$ (low-flow) is the different shape of the ventral and dorsal pressure-volume loop. As can be seen in the example in Figure 4, the dorsal slope was frequently smaller than the ventral one in the analyzed pressure range (PEEP-PEEP $\left.+5 \mathrm{cmH}_{2} \mathrm{O}\right)$. It is likely that with a higher initial PEEP (for example, a PEEP $>20$ $\mathrm{cmH}_{2} \mathrm{O}$ in the patient in Figure 4), we would have found similar ventral and dorsal values of $\mathrm{C}_{\mathrm{rs}}$. With an even higher PEEP (for example, a PEEP $>25 \mathrm{cmH}_{2} \mathrm{O}$ in the patient in Figure 4), we would have found a lower ventral $\mathrm{C}_{\mathrm{rs}}$ because of regional overdistension. One can speculate that the "best PEEP" setting would be a PEEP that leads to maximum dorsal $\mathrm{C}_{\mathrm{rs}}$ while avoiding a significant decrease in ventral $\mathrm{C}_{\mathrm{rs}}$ due to overdistension.

\section{Clinical relevance and feasibility}

The PEEP wave is a simple maneuver that can be executed repeatedly without any negative effects for the patient. In contrast, the low-flow loop requires temporary interruption of spontaneous breathing activity. In patients who are in the early weaning phase from mechanical ventilation, the administration of sedatives or even neuromuscular blocking agents is not desirable, because it may lead to an unnecessary prolongation of the weaning process. In these cases, a repeated PEEP wave maneuver-for example, before and after a decremental PEEP trial-may help in finding an individual PEEP setting. For example, the PEEP setting might be adjusted to optimize $\mathrm{C}_{\mathrm{rs}}$ in the dorsal ROI in order to avoid opening and closing of alveoli. This approach would be similar to the one that leads to improved gas exchange and lung mechanics and reduced histologic evidence of lung injury in an animal model of ARDS during CMV [14], but it would also be feasible in patients with spontaneous breathing activity.

Performing the PEEP wave maneuver and its analysis "by hand," as we did in our present study, is a rather laborious and error-prone task. An alternative method could be to perform a single PEEP step of $5 \mathrm{cmH}_{2} \mathrm{O}$ and to wait for 20 breaths to measure $\triangle \mathrm{EELV}$. However, we chose not to carry out a single PEEP step of $5 \mathrm{cmH}_{2} \mathrm{O}$, because we assumed that this would have disrupted the patient's breathing pattern by causing coughing, forced expiration or other undesirable respiratory reflex effects disturbing the measurement of $\triangle \mathrm{EELV}$.

In the future, the PEEP wave maneuver could be performed automatically by the ventilator, as it has previously been shown to be possible for CMV in a previous version of the Evita respirator [16]. The recording of a static pressure-volume loop with the super-syringe technique is an example of an even more complicated maneuver that has been greatly simplified by its automatic implementation on many ventilators in the form of a low-flow pressure-volume loop. Implementation of the PEEP wave in ventilator software as a measurement maneuver during PSV, analogous to the low-flow inflation-deflation maneuver, would make the method suitable for daily clinical use. Similarly, the regional analysis could be done automatically with a modified version of the EIT software.

\section{Conclusions}

We present a method for global and regional assessment of $\mathrm{C}_{\mathrm{rs}}$ during assisted spontaneous breathing with a PEEP wave maneuver that was analyzed with EIT. In general, the method showed good correlations to the reference values for global and regional $C_{\mathrm{rs}}$ recorded during $\mathrm{CMV}$ and during a low-flow pressure-volume loop. Performing repeated PEEP wave maneuvers starting from different PEEP levels could be suitable for identifying the PEEP level that leads to optimal dorsal lung recruitment in patients with spontaneous breathing activity.

\section{Key messages}

- A PEEP wave is a short ventilation maneuver with stepwise successive increases and decreases in PEEP by $1 \mathrm{cmH}_{2} \mathrm{O}$ for a few breaths at each step. 
- A PEEP wave maneuver can be used for determination of $\mathrm{C}_{\mathrm{rs}}$ in mechanically ventilated patients during assisted spontaneous breathing.

- Analyzing the PEEP wave with EIT allows regional assessment of $\mathrm{C}_{\mathrm{rs}}$ during assisted spontaneous breathing.

- Repeated PEEP wave maneuvers starting from different PEEP levels could be used for identifying the PEEP level that maintains optimal dorsal lung recruitment in patients with spontaneous breathing activity.

\section{Additional file}

Additional file 1: Overview of all $C_{\mathrm{rs}}$ values and of all correlations, bias and limits of agreement. Individual $C_{r s}$ values are provided in Table S1 and Table S2. An overview of all correlations, bias and limits of agreement is given in Table S3. Table S1: Overview of all global $C_{r s}$ values. Table S2: Overview of all regional $C_{\text {rs. }}$. Table S3: Overview of all correlations, bias and limits of agreement.

\section{Abbreviations \\ $\triangle P$ : Inspiratory driving pressure $\left(P_{a w}-P E E P\right) ; \Delta Z$ : Impedance change; ARDS: Acute respiratory distress syndrome; CMV: Controlled mechanical ventilation; $C_{r s}(C M V)$ : Respiratory system compliance calculated as $V_{T e} /$ $\left(P_{\text {plat }}-\right.$ PEEP); $C_{r s}($ low flow): Respiratory system compliance calculated from the low-flow pressure-volume loop; $C_{r s}$ (PEEP wave): Respiratory system compliance calculated from the PEEP wave; $C_{\text {rs: }}$ : Respiratory system compliance; EELV: End-expiratory lung volume; EIT: Electrical impedance tomography; ICU: Intensive care unit; Paw: Airway pressure; PEEP: Positive end-expiratory pressure; $P_{\text {es: }}$ : Esophageal pressure; $P_{\text {plat: }}$ Airway plateau pressure; PSV: Pressure support ventilation; RASS: Richmond Agitation and Sedation Scale; ROI: Region of interest; $T_{\text {plat: }}$ : Duration of end-inspiratory pause; $V_{T e}$ : Expired tidal volume; $V_{T i}$ : Inspired tidal volume.}

\section{Competing interests}

TB has received lecture fees from Dräger Medical. IF has received reimbursement of travel costs from Swisstom and Dräger Medical and speaking fees from Dräger Medical, respectively. DS has received lecture fees from Dräger Medical and Hamilton Medical and has received consulting fees from Dräger Medical. SB, DB and $\mathrm{GZ}$ declare that they have no competing interests.

\section{Authors' contributions}

TB participated in the design of the study, carried out the study, analyzed the data and drafted the manuscript. SB carried out the study and participated in data analysis. DB and GZ participated in data acquisition. DS participated in the design of the study and in writing the manuscript. IF participated in the design of the study, analysis and interpretation of the data and revision of the manuscript. NW conceived of the study and participated in the design of the study, analysis and interpretation of the data and revision of the manuscript. All authors read and approved the final manuscript.

\section{Acknowledgements}

We thank all the patients who participated in this study and their relatives. We also thank Tom Leenhoven (CareFusion, Yorba Linda, CA, USA) for his valuable support.

Received: 24 July 2014 Accepted: 19 November 2014 Published online: 10 December 2014

\section{References}

1. Suter PM, Fairley B, Isenberg MD: Optimum end-expiratory airway pressure in patients with acute pulmonary failure. N Engl J Med 1975, 292:284-289.

2. Amato MB, Barbas CS, Medeiros DM, Magaldi RB, Schettino GP, Lorenzi-Filho G, Kairalla RA, Deheinzelin D, Munoz C, Oliveira R, Takagaki TY, Carvalho CR:
Effect of a protective-ventilation strategy on mortality in the acute respiratory distress syndrome. N Engl J Med 1998, 338:347-354.

3. Villar J, Kacmarek RM, Pérez-Méndez L, Aguirre-Jaime A: A high positive end-expiratory pressure, low tidal volume ventilatory strategy improves outcome in persistent acute respiratory distress syndrome: a randomized, controlled trial. Crit Care Med 2006, 34:1311-1318.

4. Gattinoni L, Caironi P, Cressoni M, Chiumello D, Ranieri VM, Quintel M, Russo S, Patroniti N, Cornejo R, Bugedo G: Lung recruitment in patients with the acute respiratory distress syndrome. N Engl J Med 2006, 354:1775-1786.

5. Briel M, Meade M, Mercat A, Brower RG, Talmor D, Walter SD, Slutsky AS, Pullenayegum E, Zhou Q, Cook D, Brochard L, Richard JC, Lamontagne F, Bhatnagar N, Stewart TE, Guyatt G: Higher vs lower positive end-expiratory pressure in patients with acute lung injury and acute respiratory distress syndrome: systematic review and meta-analysis. JAMA 2010, 303:865-873.

6. The Acute Respiratory Distress Syndrome Network: Ventilation with lower tidal volumes as compared with traditional tidal volumes for acute lung injury and the acute respiratory distress syndrome. N Engl J Med 2000, 342:1301-1308.

7. Gattinoni L, Pesenti A, Avalli L, Rossi F, Bombino M: Pressure-volume curve of total respiratory system in acute respiratory failure: computed tomographic scan study. Am Rev Respir Dis 1987, 136:730-736.

8. Hickling KG: The pressure-volume curve is greatly modified by recruitment: a mathematical model of ARDS lungs. Am J Respir Crit Care Med 1998, 158:194-202.

9. Costa EL, Borges JB, Melo A, Suarez-Sipmann F, Toufen C Jr, Bohm SH, Amato MB: Bedside estimation of recruitable alveolar collapse and hyperdistension by electrical impedance tomography. Intensive Care Med 2009, 35:1132-1137.

10. Frerichs I, Dargaville PA, van Genderingen $H$, Morel DR, Rimensberger PC: Lung volume recruitment after surfactant administration modifies spatial distribution of ventilation. Am J Respir Crit Care Med 2006, 174:772-779.

11. Bikker IG, Leonhardt S, Reis Miranda D, Bakker J, Gommers D: Bedside measurement of changes in lung impedance to monitor alveolar ventilation in dependent and non-dependent parts by electrical impedance tomography during a positive end-expiratory pressure trial in mechanically ventilated intensive care unit patients. Crit Care 2010, 14:R100.

12. Lowhagen K, Lundin S, Stenqvist O: Regional intratidal gas distribution in acute lung injury and acute respiratory distress syndrome-assessed by electric impedance tomography. Minerva Anestesiol 2010, 76:1024-1035.

13. van Genderingen HR, van Vught AJ, Jansen JR: Estimation of regional lung volume changes by electrical impedance pressures tomography during a pressure-volume maneuver. Intensive Care Med 2003, 29:233-240.

14. Wolf GK, Gómez-Laberge C, Rettig JS, Vargas SO, Smallwood CD, Prabhu SP, Vitali SH, Zurakowski D, Arnold JH: Mechanical ventilation guided by electrical impedance tomography in experimental acute lung injury. Crit Care Med 2013, 41:1296-1304

15. Iotti GA, Braschi A, Brunner JX, Smits T, Olivei M, Palo A, Veronesi R: Respiratory mechanics by least squares fitting in mechanically ventilated patients: applications during paralysis and during pressure support ventilation. Intensive Care Med 1995, 21:406-413.

16. Putensen C, Baum M, Koller W, Putz G: The PEEP wave: an automated technique for bedside determination of the volume/pressure ratio in the lungs of ventilated patients [Article in German]. Anaesthesist 1989, 38:214-219.

17. Putensen C, Baum M, Hörmann C: Selecting ventilator settings according to variables derived from the quasi-static pressure/volume relationship in patients with acute lung injury. Anesth Analg 1993, 77:436-447.

18. Frerichs I, Hahn G, Hellige G: Thoracic electrical impedance tomographic measurements during volume controlled ventilation-effects of tidal volume and positive end-expiratory pressure. IEEE Trans Med Imaging 1999, 18:764-773.

19. Meier T, Luepschen H, Karsten J, Leibecke T, Grossherr M, Gehring H, Leonhardt S: Assessment of regional lung recruitment and derecruitment during a PEEP trial based on electrical impedance tomography. Intensive Care Med 2008, 34:543-550.

20. The ARDS Definition Task Force: Acute respiratory distress syndrome: the Berlin Definition. JAMA 2012, 307:2526-2533.

21. Baydur A, Behrakis PK, Zin WA, Jaeger M, Milic-Emili J: A simple method for assessing the validity of the esophageal balloon technique. Am Rev Respir Dis 1982, 126:788-791. 
22. Sessler CN, Gosnell MS, Grap MJ, Brophy GM, O'Neal PV, Keane KA, Tesoro EP, Elswick RK: The Richmond Agitation-Sedation Scale: validity and reliability in adult intensive care unit patients. Am J Respir Crit Care Med 2002, 166:1338-1344.

23. Adler A, Arnold JH, Bayford R, Borsic A, Brown B, Dixon P, Faes TJ, Frerichs I, Gagnon H, Gärber Y, Grychtol B, Hahn G, Lionheart WR, Malik A, Patterson RP, Stocks J, Tizzard A, Weiler N, Wolf GK: GREIT: a unified approach to 2D linear EIT reconstruction of lung images. Physiol Meas 2009, 30:S35-S55.

24. Pulletz S, van Genderingen HR, Schmitz G, Zick G, Schädler D, Scholz J, Weiler N, Frerichs I: Comparison of different methods to define regions of interest for evaluation of regional lung ventilation by EIT. Physiol Meas 2006, 27:S115-S127.

25. D'Angelo E, Calderini E, Torri G, Robatto FM, Bono D, Milic-Emili J: Respiratory mechanics in anesthetized paralyzed humans: effects of flow, volume, and time. J Appl Physiol 1989, 67:2556-2564.

26. Stahl CA, Möller K, Schumann S, Kuhlen R, Sydow M, Putensen C, Guttmann J: Dynamic versus static respiratory mechanics in acute lung injury and acute respiratory distress syndrome. Crit Care Med 2006, 34:2090-2098.

27. Kimball WR, Loring SH, Basta SJ, De Troyer A, Mead J: Effects of paralysis with pancuronium on chest wall statics in awake humans. J Appl Physiol 1985, 58:1638-1645

28. Faes TJ, van der Meij HA, de Munck JC, Heethaar RM: The electric resistivity of human tissues $(100 \mathrm{~Hz}-10 \mathrm{MHz})$ : a meta-analysis of review studies. Physiol Meas 1999, 20:R1-R10.

\section{Submit your next manuscript to BioMed Central and take full advantage of:}

- Convenient online submission

- Thorough peer review

- No space constraints or color figure charges

- Immediate publication on acceptance

- Inclusion in PubMed, CAS, Scopus and Google Scholar

- Research which is freely available for redistribution 